\title{
Approximations of the Generalized Log-Logistic Distribution to the Chi-Square Distribution
}

\author{
Kartika Candra Buana, Warsono, and Dian Kurniasari ${ }^{1}$
}

\begin{abstract}
The main purpose of this article is to do approximations graphically and mathematically the four-parameter generalized log-logistic distribution, denoted by $G 4 L L\left(\alpha, \beta, m_{1}, m_{2}\right)$, to the one-parameter Chi-square distribution with $v$ degrees of freedom. In order to achieve this purpose, this article creates graphically the probability density functions of both distribution and derives mathematically the MGF of the both distributions. To prove the MGF of Chi-square as a special case of the MGF of G4LL distribution, we utilized an expansion of the MacLaurin series. The results show that graphically, the Chisquare distribution can be approximated by the generalized log-logistic distribution. Moreover, by letting $\alpha=1, \beta=$ $-\ln \left(2 m_{2}\right), m_{1}=\frac{v}{2}$ and $m_{2} \rightarrow \infty$, the MGF of the G4LL distribution can be written in the form of the MGF of the Chi-square distribution. Thus, the Chi-square distribution is a limiting or special case distribution of the generalized log-logistic distribution.
\end{abstract}

\section{Keywords—chi-square distribution, generalized log-logistic distribution, moment generating function, MacLaurin series}

\begin{abstract}
Abstrak-Tujuan utama dari artikel ini adalah untuk melakukan pendekatan secara grafis dan matematis distribusi Chisquare $(v)$ melalui distribusi generalized log-logistic, dilambangkan $G 4 L L\left(\alpha, \beta, m_{1}, m_{2}\right)$. Tujuan tersebut dicapai dengan membuat grafik dari fungsi kepekatan peluang dari kedua distribusi, dan untuk membuktikan bahwa fungsi pembangkit momen dari distribusi Chi-square merupakan bentuk khusus dari fungsi pembangkit momen dari distribusi G4LL. Pembuktian melalui fungsi pembangkit momen tersebut dilakukan dengan menggunakan deret MacLaurin. Hasil penelitian menunjukkan bahwa secara grafis, distribusi Chi-square dapat didekati oleh distribusi G4LL. Selain itu, untuk $\alpha=1, \beta=-\ln \left(2 m_{2}\right), m_{1}=$ $\frac{v}{2}$ dan $m_{2} \rightarrow \infty$, distribusi Chi-square merupakan bentuk khusus dari distribusi G4LL, sehingga distribusi Chi-square dapat didekati oleh distribusi generalized log-logistic (G4LL).
\end{abstract}

Kata Kunci-distribusi Chi-square, distribusi generalized log-logistic, fungsi pembangkit momen, deret MacLaurin

\section{INTRODUCTION}

$\mathrm{T}_{1}$ he two-parameter gamma distribution is a wellknown distribution in lifitime modeling, especially in queueing systems and reliabity applications. The twoparameter gamma distribution has one shape, denoted here as $\alpha$ and one scale parameter, denoted here as $\theta$ [1]. One of attractive interpretations of this distribution occurs for integer shape parameter $\alpha$ which is suitable for modeling of a system with spare units. This property makes the gamma distribution suitable in modeling for queueing systems. Recently, the gamma distribution in modeling reliability has applied to multi-component systems by [2]. By letting the scale parameter set to two, $\theta=2$ and the shape parameter set to the degrees of freedom divided by two, $\alpha=\frac{v}{2}$, the gamma distribution reduces to the one parameter Chi-square distribution with $v$ degrees of freedom [3, 4]. As noted by some authors $[3,4,5,6]$, the one-parameter Chi-square distribution is one of the most widely used distribution in inferential statistics. The Chi-squared is commonly used for goodness of fit test of an observed to a theoretical distribution and for independence test of two criteria of qualitative data classification.

Moreover, in relating to another generalized distribution, [7] demonstrated a relation between the gamma distribution to the generalized log-logistic

${ }^{1}$ Kartika Candra Buana, Warsono, and Dian Kurniasari are with Department of Mathematics, Mathematics and Natural Science Faculty, Lampung University, Bandar Lampung, 35158, Indonesia, Email: kartikacandrabuana@yahoo.com.
(G4LL) mathematically. By deriving the moment generating function (MGF) of the two-parameter gamma and the four-parameter generalized log-logistic distributions, he concluded that the gamma distribution is special case of the generalized log-logistic distribution. As noted by some authors $[8,9,10]$, the G4LL distribution can be applied in some areas of applications. In modeling survival data, the G4LL distribution is suggested by Singh [8]. In environmental areas, $[9,10]$ propose to use the G4LL distribution. As noted by $[7,8$, $8,9,10]$, the family of G4LL distributions is quite rich and contains many well-known distributions as special cases. These distribution include the Weibull, log normal, and gamma distributions.

Therefore, the relation between the gamma and Chisquare and the study by [7] motivate our article to derive approximations the four-parameter generalized loglogistic distribution to the one-parameter Chi-square distribution. Therefore, the main purpose of this article is to do approximations graphically and mathematically the generalized log-logistic distribution to the one-parameter Chi-square distribution with $v$ degrees of freedom. In order to achieve this purpose, this article creates graphically the probability density functions of both distribution and derives mathematically the MGF of the both distributions.

The article is organized as follows. Section II provides an explanation about methods. In Section IIIA, based on graphs of the probability density functions, we discuss the similarity between the Chi-square and the generalized log-logistic distributions. Section IIIB provides a discussion of the MGF of the Chi-square and gamma distributions. To prove mathematically the Chisquare distribution is a special case of the generalized 
log-logistic distribution, Section IIIC derives parameterization of the MGF of the generalized loglogistic distribution. Finally, concluding remarks are provided in Section IV.

\section{METHOD}

\section{A. Graphs of the Probability density Functions}

In order to do approximations graphically, we develop graphs of probability density functions of Chi-square and generalized log-logistic distributions with some different values of parameters of each distribution. To create graph we use $\mathrm{R}$ language.

\section{B. The Moment Generating Function}

If $X$ is a continuous random variable, then the moment generating function of $X$ (denoted by $M_{x}(t)$ ) is defined as follows $[3,4,5,6]$ :

$$
M_{x}(t)=E\left(e^{t x}\right)=\int_{-\infty}^{\infty} e^{t x} f(x) d x
$$

To find the moment generating function of distributions, we use the probability density functions as follows.

If $X$ is a random variable of the gamma distribution, denoted by $X \sim \operatorname{Gamma}(\alpha, \theta)$. Density function of $X$ is [3, $4,5,6]$ :

$$
\mathrm{f}_{\mathrm{G}}(x)=\frac{1}{\theta^{\alpha} \Gamma(\alpha)} e^{-\frac{x}{\theta}} x^{\alpha-1} ; 0 \leq x<\infty
$$

Letting $\theta=2$ and $\alpha=\frac{v}{2}$, where $v$ is positiveintegers, then the density function becomes

$$
\mathrm{f}_{\mathrm{CHI}}(x)=\frac{1}{2^{\frac{v}{2}} \Gamma\left(\frac{v}{2}\right)} e^{-\frac{x}{2}} x^{\frac{v}{2}-1} ; 0 \leq x<\infty
$$

that is the PDF of the Chi-square distribution [5, 6]

If $X$ is a random variable of the G4LL, denoted $\mathrm{X} \sim \mathrm{G} 4 \mathrm{LL}\left(\alpha, \beta, m_{1}, m_{2}\right)$, then the PDF of the G4LL can be defined as follows $[7,8,9,10,11]$ :

$$
\begin{aligned}
& f\left(x: \alpha, \beta, m_{1}, m_{2}\right)= \\
& \left(\frac{\alpha}{x B\left(m_{1}, m_{2}\right)}\right)[F(x)]^{m_{1}}[1-F(x)]^{m_{2}}
\end{aligned}
$$

For $\alpha \geq 0$ and $\beta, m_{1}, m_{2}, x>0$, and $F(x)=$

$$
\frac{1}{\left(1+e^{-(\beta+\alpha \ln x)}\right)}
$$

In the above PDF of G4LL distribution, $\alpha$ and $\beta$ are respectively the scale parameter and the location parameter, and $\left(m_{1}, m_{2}\right)$ are the shape parameters. If $m_{1}=m_{2}=1$, the distribution reduces to the log-logistic distribution. The PDF is positively skewed if $m_{1}>m_{2}$, and the PDF is negatively skewed if $m_{1}<m_{2}$.

In this article, to determine moment generating functions we utilized MacLaurin series expansion [12]. Suppose $f$ is a function that exists for every $x$ in an open interval $I$ containing $a$. So, for every $x$ in $I$ :

$$
\begin{gathered}
f(x)=f(a)+f^{\prime}(a)(x-a)+ \\
\frac{f^{\prime \prime}(a)}{2 !}(x-a)^{2}+\cdots
\end{gathered}
$$

Equation (4) is called the Taylor series expansion for the function $f(x)$. For $a=0$, the form of series in equation (4) becomes the MacLaurin series:

$$
\begin{gathered}
f(x)=f(0)+f^{\prime}(0)(x)+ \\
\frac{f^{\prime \prime}(0)}{2 !}(x)^{2}+\cdots
\end{gathered}
$$

\section{RESULT AND DISCUSSION}

A. The shape of the Chi-Square Distribution and Generalized Log-Logistic Distribution

Figure 1 and 2 show that the graph of the PDF of the Chi-square quite similar to the graph of the PDF of the G4LL distribution. Thus, graphically, the Chi-square distribution can be approximated by the G4LL distribution. Figure 3 illustrates how the degrees of freedom effects the shape of the Chi-square distribution. The larger the values of the degrees of freedom, the distribution becomes more symetric.

From Figure 4, it can be seen that how the parameter $\alpha$ effects the scale of the G4LL distribution. Based on this figure, we observe that, as value of $\alpha$ increases, the PDF of the G4LL tends to move to the right with the height and variability relatively constant. This confirms that $\alpha$ modifies the scale of the distribution. Figure 5 shows the graph of the PDF for some values of the parameter $\beta$. This figure reveals that as value of $\beta$ increases, the shape of the G4LL distribution becomes narrower, the height of the G4LL becomes higher. Thus, this suggests that $\beta$ effects the variability and height of the G4LL distribution. Moreover, Figure 6 presents the graph of the PDF for some values of the parameter $m_{2}$. According to this figure, it is clear that as $m_{2}$ increases, the shape of generalized log-logistic distribution becomes smaller. It means that the variability becomes lower when the value of $m_{2}$ increases. But, as $m_{2}$ increases, the height of the G4LL distribution becomes higher.

\section{B. The Moment Generating Function of the Chi-square Distribution}

In this section we derive the MGF of the Chi-square distribution. If $X \sim \chi_{(v)}^{2}$ then the moment generating function of the Chi-square can be expressed as follows:

$$
\begin{aligned}
& M_{C H I}(t)=E\left(e^{t x}\right)=\int_{-\infty}^{\infty} e^{t x} f(x) d x \\
& =\int_{0}^{\infty} e^{t x} \frac{1}{2^{\frac{v}{2}} \Gamma\left(\frac{v}{2}\right)} e^{-\frac{x}{2}} x^{\frac{v}{2}-1} d x \\
& =\frac{1}{2^{\frac{v}{2}} \Gamma\left(\frac{v}{2}\right)} \int_{0}^{\infty} x^{\frac{v}{2}-1} e^{-x\left(\frac{1}{2}-t\right)} d x
\end{aligned}
$$

If we let $y=x\left(\frac{1}{2}-t\right)$, then $x=\frac{2 y}{1-2 t}$ and $d x=$ $\frac{2}{1-2 t} d y$, so equation (6) becomes

$M_{C H I}(t)=$

$$
\frac{1}{2^{\frac{v}{2}} \Gamma\left(\frac{v}{2}\right)} \int_{0}^{\infty}\left(\frac{2 y}{1-2 t}\right)^{\frac{v}{2}-1} e^{-y} \frac{2}{1-2 t} d y
$$




$$
=\frac{1}{2^{\frac{v}{2}} \Gamma\left(\frac{v}{2}\right)}\left(\frac{2}{1-2 t}\right)^{\frac{v}{2}} \int_{0}^{\infty} y^{\frac{v}{2}-1} e^{-y} d y
$$

It is well-known that $\int_{0}^{\infty} y^{\alpha-1} e^{-y} d y$ is Gamma function, that is $\Gamma(\alpha)[4,5,6]$, then $\int_{0}^{\infty} y^{\frac{v}{2}-1} e^{-y} d y=\Gamma\left(\frac{v}{2}\right)$.

So that,

$$
M_{C H I}(t)=\frac{1}{(1-2 t)^{\frac{v}{2}}}
$$

Therefore, the MGF of the Chi-square can be expressed:

$$
M_{C H I}(t)=(1-2 t)^{-\frac{v}{2}}
$$

Now, the MGF of the gamma distribution can be written as follows $[4,5,6]$ :

$$
M_{\text {GAMMA }}(t)=\frac{1}{(1-\theta t)^{\alpha}}=(1-\theta t)^{-\alpha}
$$

By letting $\alpha=\frac{v}{2}$ and $\theta=2$,equation (8) can be rewritten as follows:

$$
M_{\text {GAMMA }}(t)=(1-2 t)^{-\frac{v}{2}}
$$

This is exactly the same as the MGF of the Chi-square distribution.

\section{Parameterization of Moment Generating Function of G4LL Distribution}

Based on the PDF of the generalized log-logistic distribution in equation (3), using MGF definition and MacLaurin's series [7] mathematically derives the MGF of the generalized log-logistic distribution, and it can be written as the following equation:

$$
\begin{aligned}
& M_{G 4 L L}(t)= \\
& \sum_{n=0}^{\infty} \frac{\left(t e^{-(\beta / \alpha)}\right)^{n}}{n !} \frac{\Gamma\left(m_{1}+\frac{n}{\alpha}\right) \Gamma\left(m_{2}-\frac{n}{\alpha}\right)}{\Gamma\left(m_{1}\right) \Gamma\left(m_{2}\right)}
\end{aligned}
$$

For $m_{2} \rightarrow \infty, \alpha=1$, and $\beta=-\ln \left(\theta m_{2}\right)$, [1] proved that equation (10) equals to the MGF of the gamma distribuion as stated in equation (8). Therefore, $\operatorname{GLLD}\left(\alpha, \beta, m_{1}, m_{2}\right)$ convergent to the Gamma distribution.

Let $\quad \alpha=1, \beta=-\ln \left(2 m_{2}\right), m_{1}=\frac{v}{2}$ and $\quad m_{2} \rightarrow \infty$, equation (10) can be expressed as follows:

$$
\begin{aligned}
& M_{G 4 L L}(t)=\lim _{m_{2} \rightarrow \infty} M_{x}(t) G L L \\
& \left(\alpha=1, \beta=-\ln \left(2 m_{2}\right), m_{1}=\frac{v}{2}, m_{2}\right) \\
& \quad=\lim _{m_{2} \rightarrow \infty} \sum_{n=0}^{\infty} \frac{\left(t e^{-(\beta / \alpha)}\right)^{n}}{n !} \frac{\Gamma\left(m_{1}+\frac{n}{\alpha}\right) \Gamma\left(m_{2}-\frac{n}{\alpha}\right)}{\Gamma\left(m_{1}\right) \Gamma\left(m_{2}\right)} \\
& =\lim _{m_{2} \rightarrow \infty} \sum_{n=0}^{\infty} \frac{\left(t e^{\left.-\left(\frac{-\ln 2 m_{2}}{1}\right)\right)^{n}}\right.}{n !} \frac{\Gamma\left(\frac{v}{2}+\frac{n}{1}\right) \Gamma\left(m_{2}-\frac{n}{1}\right)}{\Gamma\left(\frac{v}{2}\right) \Gamma\left(m_{2}\right)}
\end{aligned}
$$

$$
\begin{aligned}
= & \lim _{m_{2} \rightarrow \infty} \sum_{n=0}^{\infty} \frac{\left(t e^{\left(l n 2 m_{2}\right)}\right)^{n}}{n !} \frac{\Gamma\left(\frac{v}{2}+\frac{n}{1}\right) \Gamma\left(m_{2}-n\right)}{\Gamma\left(\frac{v}{2}\right) \Gamma\left(m_{2}\right)} \\
= & \lim _{m_{2} \rightarrow \infty} \sum_{n=0}^{\infty} \frac{\left(t e^{\left(l n 2 m_{2}\right)}\right)^{n}}{n !} \frac{\Gamma\left(\frac{v}{2}+n\right) \Gamma\left(m_{2}-n\right)}{\Gamma\left(\frac{v}{2}\right) \Gamma\left(m_{2}\right)} \\
= & \lim _{m_{2} \rightarrow \infty} \sum_{n=0}^{\infty} \frac{\left(t 2 m_{2}\right)^{n}}{n !} \frac{\Gamma\left(\frac{v}{2}+n\right) \Gamma\left(m_{2}-n\right)}{\Gamma\left(\frac{v}{2}\right) \Gamma\left(m_{2}\right)} \\
= & \lim _{m_{2} \rightarrow \infty}\left[\frac{\left(t 2 m_{2}\right)^{0}}{0 !} \frac{\Gamma\left(\frac{v}{2}+n\right) \Gamma\left(m_{2}-0\right)}{\Gamma\left(\frac{v}{2}\right) \Gamma\left(m_{2}\right)}+\right. \\
& \frac{\left(t 2 m_{2}\right)^{1}}{1 !} \frac{\Gamma\left(\frac{v}{2}+1\right) \Gamma\left(m_{2}-1\right)}{\Gamma\left(\frac{v}{2}\right) \Gamma\left(m_{2}\right)}+ \\
& \left.\frac{\left(t 2 m_{2}\right)^{2}}{2 !} \frac{\Gamma\left(\frac{v}{2}+2\right) \Gamma\left(m_{2}-2\right)}{\Gamma\left(\frac{v}{2}\right) \Gamma\left(m_{2}\right)}+\cdots\right] \\
= & \lim _{m_{2} \rightarrow \infty} 1+2 t \frac{\Gamma\left(\frac{v}{2}+1\right)}{\Gamma\left(\frac{v}{2}\right)} \lim _{m_{2} \rightarrow \infty} m_{2} \frac{\Gamma\left(m_{2}-1\right)}{\Gamma\left(m_{2}\right)}+ \\
& \frac{(2 t)^{2}}{2 !} \frac{\Gamma\left(\frac{v}{2}+2\right)}{\Gamma\left(\frac{v}{2}\right)} \lim _{m_{2} \rightarrow \infty}\left(m_{2}\right)^{2} \frac{\Gamma\left(m_{2}-2\right)}{\Gamma\left(m_{2}\right)}+\cdots \\
= & 1+2 t \frac{v}{2}+\frac{(2 t)^{2}}{2 !} \frac{v}{2}\left(\frac{v}{2}+1\right)+\cdots+\cdots \\
= & (1-2 t)^{-\frac{v}{2}}(\operatorname{based} \text { on MacLaurin's series) }
\end{aligned}
$$

Therefore, the MGF of the G4LL distribution as stated in the equation (10) becomes

$$
M_{G 4 L L}(t)=(1-2 t)^{-\frac{v}{2}}
$$

Equation (12) is exactly the same as the moment generating function of the Chi-square distribution . Thus, Chi-square distribution is a limiting case or limit distribution of generalized log-logistic distribution with parameters of $\alpha=1, \quad \beta=-\ln \left(2 m_{2}\right), m_{1}=\frac{v}{2} \quad$ and $m_{2} \rightarrow \infty$

\section{CONCLUSION}

Graphically, the Chi-square distribution can be approximated by the generalized log-logistic distribution. Based on parametrization, $\alpha=\frac{v}{2}$ and $\theta=2$, of the moment generating function of the gamma distribution can be reduced to the moment generating function of the Chi-square distribution. In other words, the Chi-square distribution can be approximated by the gamma distribution. By letting $\alpha=1, \beta=-\ln \left(2 m_{2}\right), m_{1}=\frac{v}{2}$ and $m_{2} \rightarrow \infty$, the moment generating function of the generalized log-logistic distribution can be written in the form of the moment generating function of the Chisquare distribution. Thus, the Chi-square distribution is a limiting or special case distribution of the generalized $\log$-logistic distribution. Mathematically, therefore, the Chi-square distribution can be approximated by the generalized log-logistic distribution as well. 


\section{ACKNOWLEDGEMENT}

The authors would like to thank anonymous refereces and editors for valuable comments on the earlier version of this article, and that have significantly improved this article.

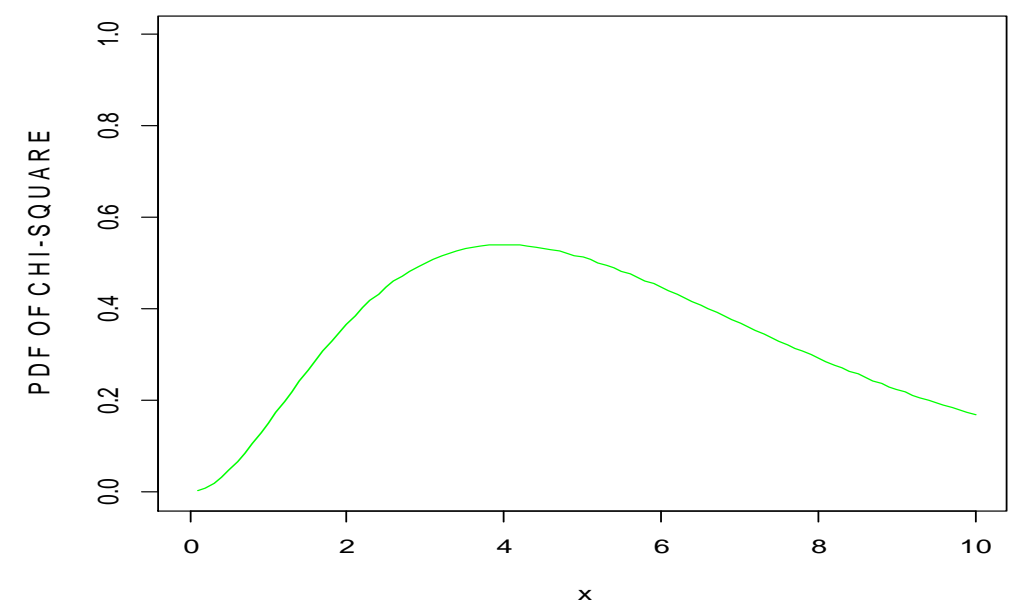

Figure 1. Graph of the Chi-square distribution $(v=6)$

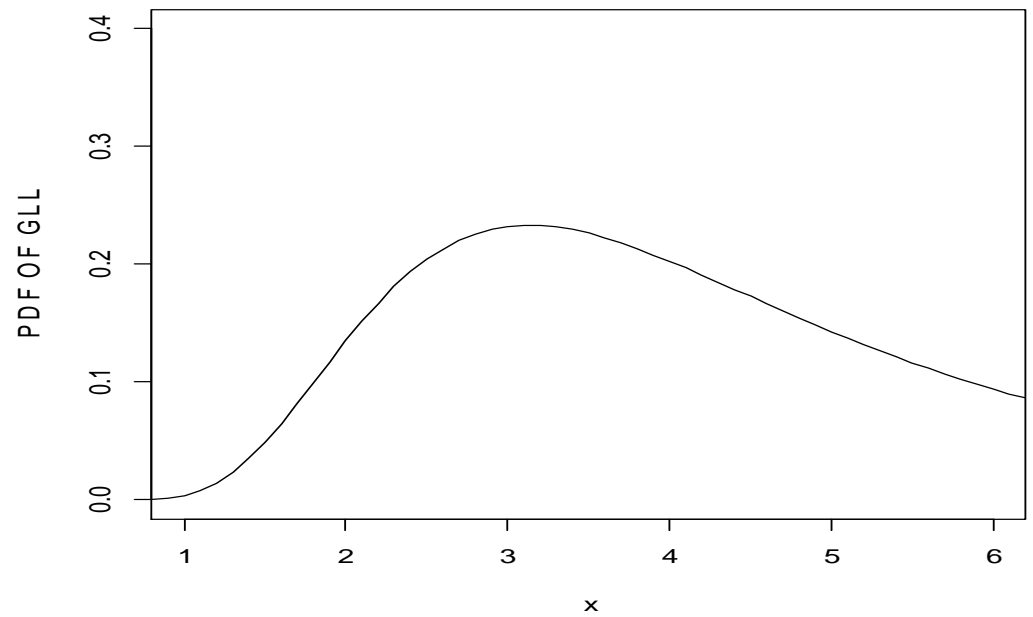

Figure 2. Graph of thegeneralized log-logistic distribution with $\alpha=1, \beta=-\log \left(2 m_{2}\right), m_{1}=30, m_{2}=5$

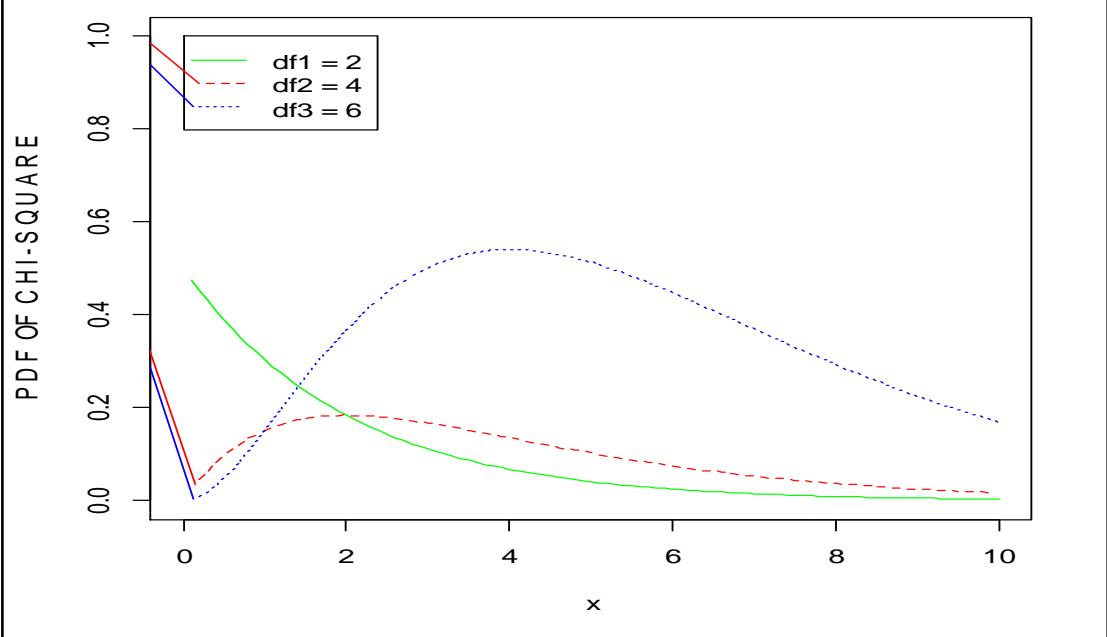

Figure. 3. Graph of theChi-square distribution for $v=2, v=4$, and $v=6$ 


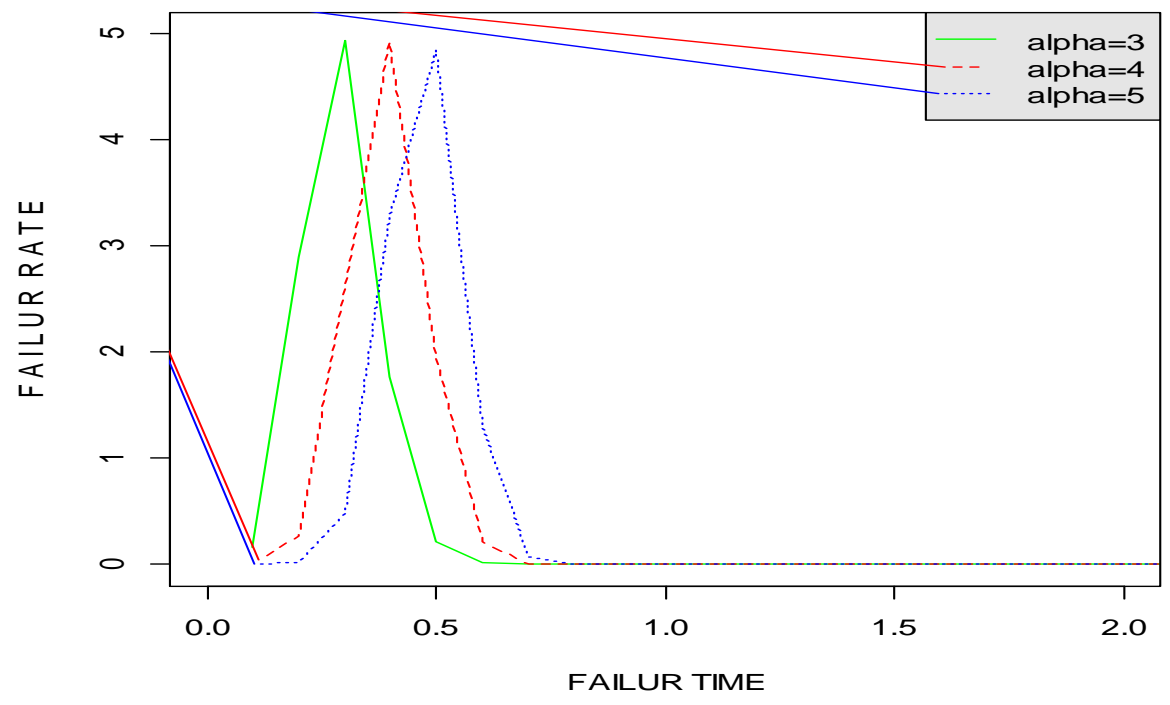

Figure 4. Graph of the G4LL distribution graph with $\alpha=3, \alpha=4, \alpha=5, \beta=2, m_{1}=2$ and $m_{2}=10$

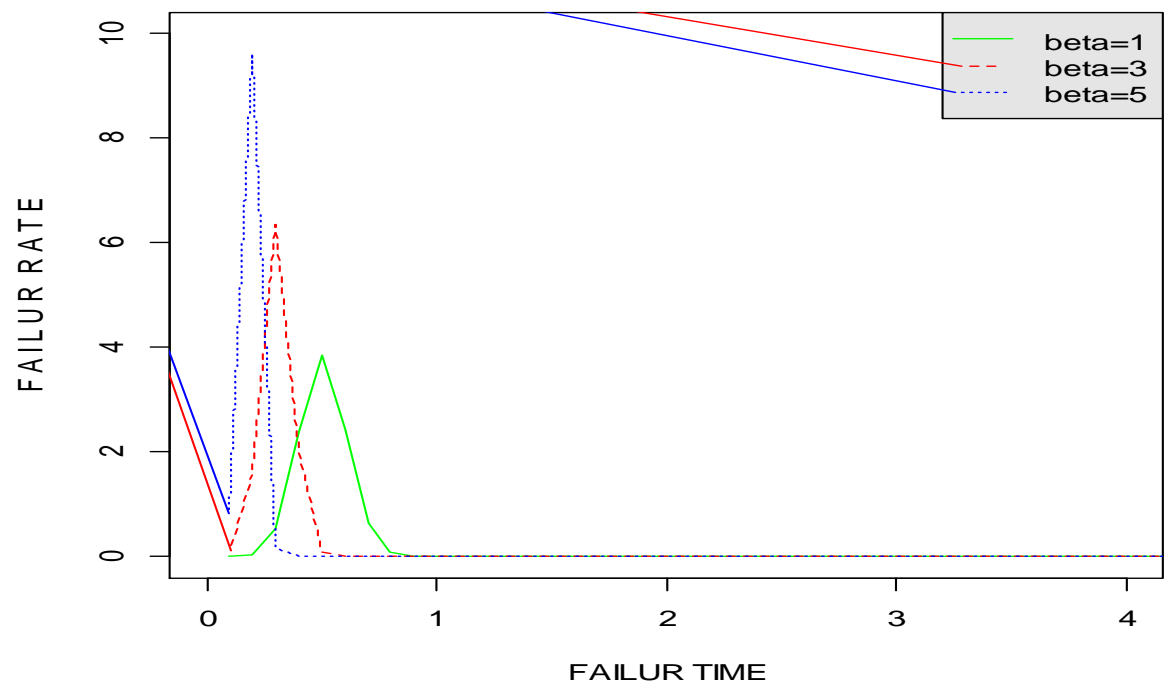

Figure 5. Graph of the G4LL distribution graph with $\beta=1, \beta=3, \beta=5, \alpha=4, m_{1}=2$ and $m_{2}=10$ 


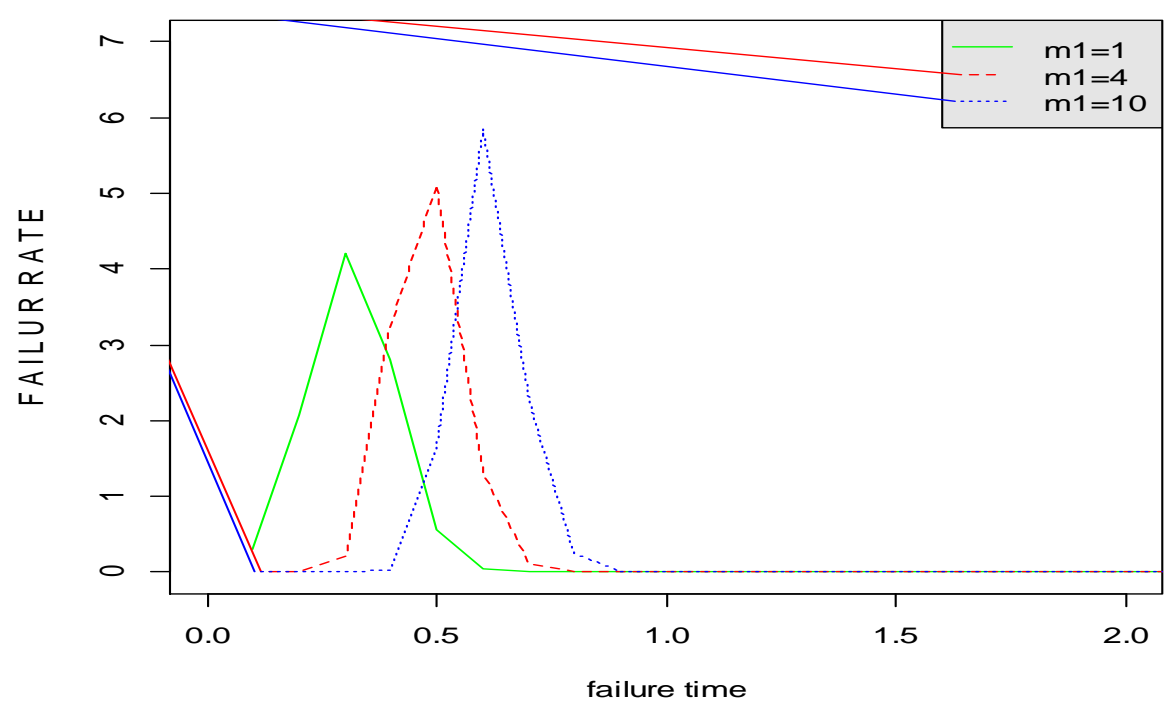

Figure 6. Graph of the G4LL distribution graph with $m_{1}=1, m_{1}=4, m_{1}=10, \alpha=4, \beta=2$ and $m_{2}=10$

\section{REFERENCES}

[1] C.G. Khatri, and C.R. Rao, "Some Characterizations ofthe Gamma Distribution", Sankhya The Indian Journal of Statistics, Series A, 30, 157-166. 1968.

[2] J. Gogoi and M. Borah. "Estimation of Reliability For Multicomponent Systems using Exponential, Gamma, and Lindley Stress-Strength Distributions", Journal of Reliability and Statistical Studies; ISSN (Print): 0974-8024, (Online): 2229. 5666,Vol. 5, Issue 1 (2012): 33-41.

[3] C. Walck. "Hand-book on Statistical Distributions for Experimentalists", Internal Report SUF-PFY/96-01. University of Stockholm, 2001.

[4] K. Krishnamoorthy. "Handbook of statistical distributions with applications", Taylor \& Francis Group, LLC Chapman \& Hall/CRC is an imprint of Taylor \& Francis Group, an Informa business 2006 by Taylor \& Francis Group, LLC. Boca Raton, FL, 2006.

[5] R.V. Hogg, dan A.T. Craig, "Introduction to Mathematical Statistics”, Prentice-Hall Inc, New Jersey, 1995.
[6] G. Cassella, and R.L. Berger. "Statistical inference", Wadsworth Inc., Belmont, California, 1990.

[7] Warsono, "Remarks on Moment Properties of Generalized Distributions", Proceedings of The Third International Conference on Mathematics and Natural Sciences. ITB, Bandung, 2010.

[8] K.P. Singh. "A Generalized Log-Logistic Regression Model For Survival Analysis: Hazard Rate Characteristics",Biometrie Praximetrie 29: 63-74, 1989.

[9] K.P. Singh, A.A. Bartolucci, and Burgard, S.L. 1994. "Two-step procedure for survival data", Biometrie-Praximetrie 34: 1-12.

[10] K.P. Singh, Warsono, and A.A. Bartolucci, "Generalized LogLogistic Model for Analysis of Environmental Pollutant Data", Proc. Int. Congress on Modeling and Simulation. Hobart, Tasmania. December 8-11 1997.

[11] Warsono, M. Usman, and Nusyirwan. "On the estimation of the generalized log-logistic distribution with applications to pollutant concentration data", Forum StatistikadanKomputasi. EdisiKhusus: 74-77, 2000

[12] M.R. Spiegel. "Mathematical Hand Book of Formulas and Tables", McGraw-Hill Inc., 1968. 